\title{
Individualism in Robert Frost’s Design
}

\author{
LI Rong \\ Chengdu Textile College, Chengdu, China
}

\begin{abstract}
Robert Frost's Design presents us a scene that a white spider is sitting on a white flower holding up a white moth. It seems that pessimism is hanging over and the poet is helplessly trapped in despair. However, influenced by Transcendentalism, this poem exemplifies Frost’s belief in “responsible individualism” and echoes a brave man's optimism when challenged by the "design of darkness". The literary interpretation of Design is going to reveal how we get such a conclusion.
\end{abstract}

Keywords: Design, individualism, transcendentalism, literary interpretation

\section{Introduction}

Design (1922)

I found a dimpled spider, fat and white, On a white heal-all, holding up a moth Like a white piece of rigid satin clothAssorted characters of death and blight Mixed ready to begin the morning right, Like the ingredients of a witches' brothA snow-drop spider, a flower like a froth. And dead wings carried like a paper kite.

What had that flower to do with being white, The wayside blue and innocent heal-all? What brought the kindred spider to that height, Then steered the white moth thither in the night? What but design of darkness to appall?If design govern in a thing so small.

It is said that the Design is "meditation on human attempts to see order in the universe and failures at perceiving the order that is actually present in nature", "finding evil in innocent”, "investing an air of fear and fatalism”, etc. Most of the current criticisms about Robert Frost's Design unanimously pay utmost attention to the pessimistic side revealed by such dictions as "darkness", “evil”, "fete”, etc. No doubt that all are admirably suitable to this poem in certain aspects. But it is axiomatic that all of them cannot exhaust the manifold interpretive possibilities of a worthwhile literary work and such generalization risks oversimplification. Deeper literary interpretations of this poem reveal completely opposite emotions between lines. Although confronting

LI Rong, lecturer, M.A., Assistant in International Affairs Office, English Teacher in Foreign Language School, Chengdu Textile College, Chengdu, China. 
the threat of "design of darkness" and the evil of "design of night", the poet still holds strong belief in "Individualism" and the rebelling force between lines can also be felt.

\section{The Manuscrip: In White}

Here is Frost's manuscrip version of 1912 titled In White: (Montiero, 1988)

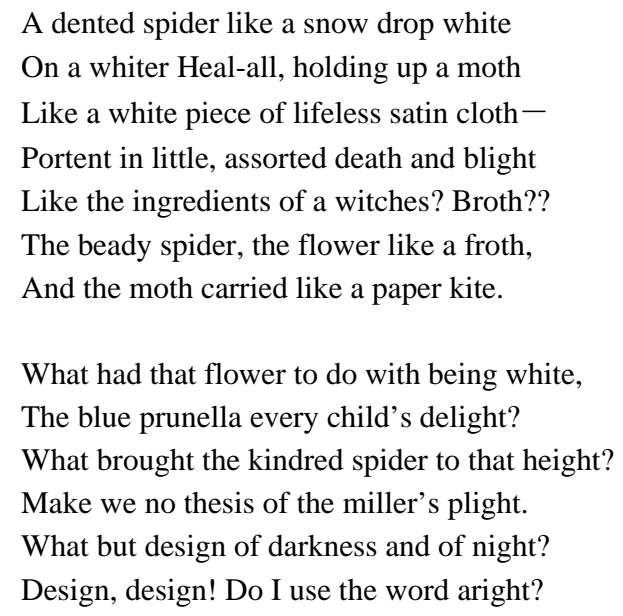

It would be argued that how the poet can be optimistic in a world full of "assorted characters of death and blight" and how the mages of a "snow-drop spider", "a flower like a froth”, and a moth with "dead wings carried like a paper kite" (WU, 1990) are able to encourage a sense of optimistic individualism. As we know, the final version of the poem Design was first published in 1922, 10 years after which the manuscript was finished. The interpretation of the two versions through comparison can afford many profound clues toward those ambivalence and evidence for our argument by tracing Frost's mind as he reworked the draft and rethought his ideas during these years.

\section{Literary Interpretations}

Frost's optimistic air is invested first of all in the title "In White" of the draft. "Whiteness" not only indicates the poem's principle image and motif, but also symbolizes purity and goodness contrary to the death and evil of the design in blackness. What Frost wants to portray in his poem is the "design in white" which can much more impressively stand out against the presentation, that is to say, the "design in darkness". The introduction of the poet's voice ("I") into the fist line in Design gives the poet prominence than he did in the manuscript, which begins only with a sentence fragment ("A dented spider like a snow drop white"). The simile, "like a snow drop white”, disappears along with another descriptive word "dented". In their place, Frost offers three adjectives: "dimpled", "fat”, and "white”, which come from our regular description of a baby. A newly-born baby after ten-month expecting undoubtedly brings excitement, gaiety, and life to its parents as well as its other family members. The neutrally descriptive word ("dented") is also replaced by "dimpled" with its sentimental denotation through which Frost announces his themes and reveals his ironic approach. From the reversion of the first line, we may hint that Frost intends to infuse life to death, happiness to sadness and sets them contradictory to each other for an ironic tone. 
The three lines in the beginning of two versions picture us what the poet sees. The moth, described initially as "a white piece of lifeless cloth" becomes "rigid stain cloth". "Lifeless" is only vague description of the moth’s state, but it does not accurately picture the tableau of the spider holding up the moth. "Rigid" vividly impresses us of the spider's strong unwillingness to give up its bag even though it does not have the opportunity to enjoy it any more. Although the body of the spider is as stiff as that of the moth in a state of rigor mortis, its struggle for survival probably cannot escape the reader's attentive and sensitive eyes. "Stain cloth" is originally used for making the ceremonial dress in wedding rituals. In this way, it is the symbol of love and innocence and functions the same as "white” and “dimpled” do. Again we can sense Frost's ironic tone in his adoption of it to represent a horrible picture of death and killing. The capitalized "Heal-all” in the manuscript implies the existence of God, but finally Frost gives up the capitalization and blurs the traditional connotations on God as designer or creator of nature.

Line four in the manuscript is rather limp and awkward. The semi-rhetorical question, "saw ever curious eyes so strange a sight?” seriously deflects argument of this poem. In the final version, Frost moves the second half of the original fifth line, "assorted death and blight", to line four and at the same time extends it to "assorted characters of death and blight”, thereby introducing the important metaphor to the "witches' broth" in line seven. Line six stays almost intact and no longer asks a question. Indeed the two questions which dominate the octave in the first version are strategically omitted so as to accumulate all the attention to the last but only question in the sestet of the poem. The additional line five, "mixed ready to begin the morning right", in the final version beautifully develops the sad tone in the "assorted characters of death and blight". As very beginning of a new day, morning breeds expectations and hopes which can stimulate our great enthusiasm to achieve them. Meanwhile, the brightness of the day brought by the fresh sun disperses the blackness of night. Therefore, Frost carefully infuses "death and blight" with "life and renewal" to accompany the ironic tone with an optimistic voice even if it is very thin.

In the second half of the first stanza, "Mixed ready to begin the morning right" is added to the final version. The introduction of "morning”, "right” contrasts to "dark", "blight”. Frost uses iambic pentameter to show the changing mood from negative to positive, to remind us the right morning will begin although there exist "death and blight". There are many changes in the last two lines of the octet: The "beady spider" is turned into "snow-drop spider", reinstating the adjective which Frost had discarded from the first line in the manuscript poem; the definite article "the" modifies "spider and flower" into the indefinite article "a", the "moth" into "dead wings”. Those changes not only achieve precision but also polish Frost's mind. "Snow-drop” accomplishes the aim at keeping the idea of coldness and death before us. The shift of articles diverts our attention from individuality to universality in that it emphasizes the omniscience of the design of nature. Any careful observer of nature among who Frost certainly can tell you that there is a perfectly logical explanation for the apparent coincidence of three white creatures appearing together. This is the design governed by the inexorable laws of nature, the law of decay, death, and physical extinction beyond humankind's manipulation, so do we need to be appalled by it? (“What to appall?”). In the last line of the octave, "moth” is turned into "dead wings”, but the simile "like a paper kite" is happily retained in that this simile remind us of the implicitly "childlike" description of the spider in the opening line. Although the image of white "dead wings" moves toward paradox, it can still be 
reminiscent of its energetic flight through the connotation of "wings". Furthermore, the word "carried" gives a sense of weight that probably can be felt in a living moth instead of the dead.

Comparing with the two versions, we can see little survives intactness in the 1912's version except the ninth line, "What had that flower to do with being white" and this much about his basic poem Frost had been sure of all long.

The appositive clause which constitutes the Line 10, “the blue prunella every child's delight”, obviously adds nothing to the argument of the poem except the new information that the heal-all is also known as the prunella. The "wayside blue" and "innocent heal-all” take the place of "prunella” and "every child's delight" respectively by which it can push the argument a step further. "Wayside" partakes somehow of the universal, in doing so, it may arouse our sympathy with the little creature. "Blue", sharply contradictory to its current whiteness, enormously appalls us for the flower whose innocence even the poet cannot help confessing. The alternative of "prunella" or "heal-all" is also of substantive significance besides its rhetoric function. It is competent to heal all of course including itself. In this sense, Frost advocates his optimistic attitudes at least his positive expectation for its recovery from the current whiteness to regain bright blueness when making the choice to name it.

The twelfth line, “make we not thesis of the miller's plight”, in the draft is propped completely and fittingly. Rather than the somewhat disingenuous admonition that avoids making a thesis out of this tableau, Frost chooses to deepen the question he asks about the tableau he has witnessed by inquiring not only "what brought the kindred spider to that height”, but also what "then steered the white moth thither in the night?”. The meditation on all these questions achieves a cumulative effect on the final acquisition presented by the rhetorical question: "What but design of darkness appall?”

The last line of the manuscript gives way to a conditional clause in the final version. On the one hand, “Design, design! Do I use the word aright?” is crudely rhythmic without the force to resolve the poem formally; on the other hand, to end the poem with the tentative clause "if design govern in a thing so small" further adumbrates thematic resolution. The partly ambiguous summing-up proves the possibility of the optimistic reading of Design which sounds seemingly queer. "Design" in the last line specifically refers to "design of nature" in that the whole poem exhibits a natural scene in which a white spider sits on a white flower holding up a white moth. Then we can sense the relationship between "the design of nature" and "the design of darkness": The "design of darkness" is subordinate to the "design of nature" in terms of the fact that the darkness of night is created by nature in a wider sense. Based on our clarification of the two kinds of "designs”, we may rearrange and rewrite the tow lines as following to achieve explicitness: If design of nature governs in anything at all, what to appall but design of darkness? Philip Wheelwright once indicates that "Death is but an interim evil; it occurs periodically, but there is the assurance of new life ever springing up to take its place.” (Guerin, Labour, Morgan, Reesman, \& Willingham, 2004). Therefore, there is no need for us to be appalled by the "design of darkness" which succumbs itself to the much more powerful "design of nature". Moreover, the transitive conjunction "but" voices the poet's ("my") defiance and despise to the "design of darkness" in spite of its horrifyingly designed picture. The rhetorical question lends force to the individual ("I") with the belief in the omniscient existence as well as the governing power of design of nature to refuse to pledge allegiance to the "design of darkness". 


\section{Conclusion}

A comparison between the initial and the definite version of Design helps us ascertain the poet's final intention. Despite some internal revisions and the reshaping of several lines, it remained fundamentally consistent in the endemically irony which is still able to locate Frost's optimistic attitudes when facing the pessimistic "design of darkness". Although he intends to enjoy a kind of pagan delight in nature, his Design can still reminds us of his "responsible individualism controlled by an inner mandate” (G. Perkins \& B. Perkins, 1999) influenced by the Transcendentalism of earlier New Englanders like Thoreau and Emerson. Lecturing in 1834 on the theme of man's relationship to the globe, Emerson remarked: “......I am thrilled with delight by the choral harmony of the whole Design! It is all design. It is all beauty. It is all astonishment”. It is obvious that we cannot identify the white without the reference to the black. How can we enjoy the brightness brought by the sunrise without experiencing the blackness after the sunset? The accumulated optimistic atmosphere is enhanced in the procession of this sonnet through diction, ironies, and comparisons, meanwhile, finds its loudest resonance in the conclusion which serves as the turning point of the whole poem both in depiction and emotion. The Design is "all beauty”. Actually, Frost is not allegiant to fatalism or depressed by the horrible picture despite his possible astonishment when first encountering it by chance. Just as he said that he had only "lover's quarrel with the world”. Frost’s Design really provides an immediate experience which "ends in wisdom, even though it does not "begin in delight” (G. Perkins \& B. Perkins, 1999)

\section{References}

Guerin, W. L., Labour, E., Morgan, L., Reesman, J. C., \& Willingham, J. R. (2004). A handbook of critical approaches to literature. Shanghai: Foreign Language Teaching and Research Press \& Oxford University Press.

Montiero, G. (1988). On Design. Robert Frost and the New England Renaissance. Lexingto: The University Press of Kentucky.

Perkins, G., \& Perkins, B. (1999). The American tradition in literature (Vol. 2). New York: Mcgraw-Hill Collage.

WU, W. R. (1990). History and anthology of American literature (Vol. 2). Beijing: Foreign Language Teaching and Research press. 